\title{
Biometric Security Identification System for Internally Displaced Persons (IDPs) in North-East Nigeria
}

\author{
${ }^{1}$ Musa I. Umar, ${ }^{2}$ Deborah U. Ebem \& ${ }^{3}$ Groupson-Paul Okechukwu \\ 1\&2Department of Computer Science, University of Nigeria, Nsukka., Enugu State, Nigeria \\ ${ }^{3}$ Department of Political Science, Federal University, Ndufu Alike Ikwo, Abakaliki, Nigeria. \\ E-mails: musa.umar.pg76718@unn.edu.ng; deborah.ebem@unn.edu.ng; Okechukwu.groupson@funai.edu.ng \\ Phones: +234 803761 5708, +234 805281 0722; +2348023368467
}

\begin{abstract}
There are provisions for accommodating Internally Displaced Persons (IDPs) in North-East Nigeria. However, there are some challenges in the camps where these IDPs are accommodated. They include issues such as killings, kidnappings, stealing, rapes, and shortage of food and diversion of relief materials, among others. These challenges have made life difficult for the IDPs, donor agencies and the government at large in managing and securing the camps with respect to security provision and the distribution of relief materials to the IDPs. This study notes that the existing manual method of keeping records of IDPs in the camps is tedious and allows insecurity and improper documentation. A web-based application which provides a means of ensuring adequate documentation of IDPs by capturing the necessary data to ensure the proper identification and accounting of the IDPs is developed. Also, the use of fingerprint identification system which is a form of biometric identification is embedded in this application. The application utilizes a portable fingerprint scanner as its input in acquiring fingerprints of the IDPs. It verifies the fingerprint by displaying the associated image and other personal details of the internally displaced person. The system is also capable of querying the database for the IDPs. The system was developed using PHP, CSS, JAVA and MYSQL. Object Oriented Analysis and Design Methodology (OOADM) was used to analyze the system and Unified Modeling Language (UML) was used to model the software. The information generated from the enrollment and biometric capturing of IDPs will effectively verify and identify the IDPs. This developed system will be used to enhance the security, the distribution of relief materials, and the managing of IDPs in the camps.
\end{abstract}

Keywords: IDPs, fingerprints, facial recognition, security and displacements

Aims Research Journal Reference Format:

Musa I. Umar, Deborah U. Ebem \& Groupson-Paul Okechukwu (2019): Biometric Security Identification System for Internally

Displaced Persons (IDPs) in North-East Nigeria. Advances in Multidisciplinary Research Journal. Vol. 5. No. 2, Pp 11-24.

Article DOI: dx.doi.org/10.22624/AIMS/V5N2P2

\section{INTRODUCTION}

For the past 50 years of Nigeria's independence, violent conflicts have trigged off forced migration and internal displacement of people in the nation. Other causes of displacement include natural disasters and environmental degradation, inter-communal/inter-ethnic clashes, disputes over land, boundary conflicts between indigenous people and settlers, communal and ethno-religious clashes, as well as electoral violence. The highest recorded number in the last decade was due to insurgency in the northeast of the country where a spate of violent attacks since 2009 has left well over two million people displaced within and across the borders to neighbouring countries, especially over the past three years (Mohammed 2017). As at October 2016, the International Organization for Migration (IOM) in collaboration with National Emergency Management Agency (NEMA) in its $12^{\text {th }}$ round of Displacement Tracking Matrix (DTM) programme estimated the total number of Internally Displaced Persons (IDPs) at 2,155,618 across thirteen (13) states in Nigeria. As at December 2016, the DTM Round 13 Report estimated 1,770,440 IDPs in the northeast alone (Mohammed 2017). 
Insurgency has become a threat to global peace and security in the $21^{\text {st }}$ century due to the fact that it constitutes the highest contributor to humanitarian crises in the form of rise in human casualties, internally displaced persons (IDPs), refugee disasters, food insecurity and spread of various diseases (Emmanuelar (2015), Onor K.C. \& Okechukwu GP (2017)). In Nigeria the activities of insurgency have caused many communities to run from their homes to various IDPs camps across Nigeria.

Nigeria, located in West Africa, is one of the world's largest oil producers and Africa's most populated country, with an estimated population of 182 million and more than half of her people are under 30 years of age (National Planning Commission 2016). Despite her abundant natural resources and wealth, she remains one of the world's poorest countries with more than 70\% (about 140 million Nigerians) living on less than USD 1.25 per day (Mohammed 2017) and ranking 152 of 187 in Human Development Index (Mohammed 2017). Nigeria is divided into 36 states within six geo-political zones viz: North-Central, NorthWest, North-East, South-West, South-South, and South-East. The figure below shows the map of Nigeria showing areas with the highest displaced persons in North-East Nigeria. The North-East comprises six states: Adamawa, Bauchi, Borno, Taraba and Yobe. Social and economic indicators are one of the lowest in that zone compared to other parts of the country (Mohammed 2017). Figures 1 and 2 below depicts a map of Nigeria showing areas with the highest displaced Persons in North East and an IDP camp in NorthEast Nigeria respectively.

\section{Nigeria : plus de $\mathbf{2}$ millions de déplacés}

\section{5\% des déplacés ont fui les violences des islamistes de Boko Haram}

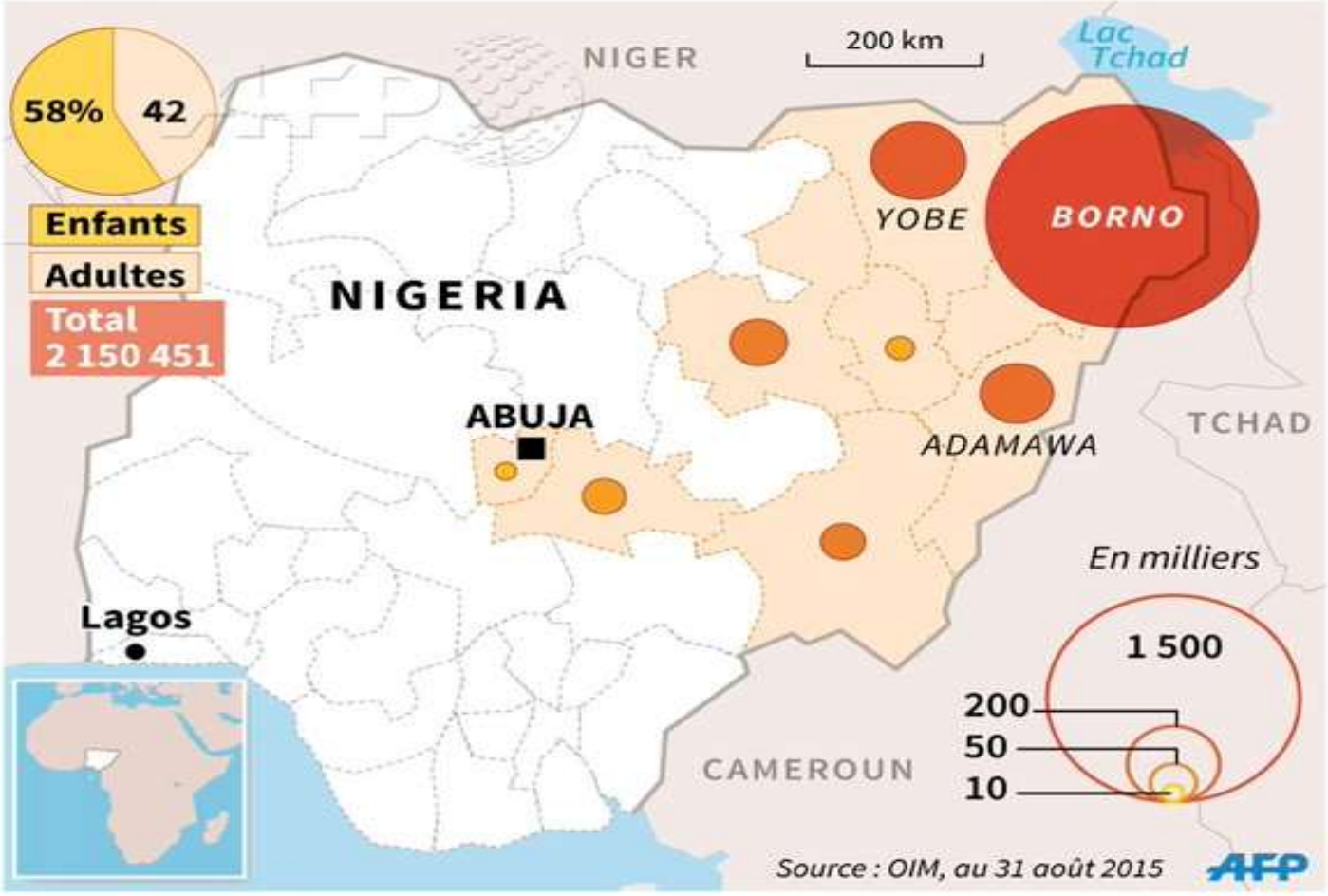

Figure 1: Map of Nigeria showing areas with the highest displaced persons in North-East Nigeria Source: OIM, $31^{\text {st }}$ Oct 2015 


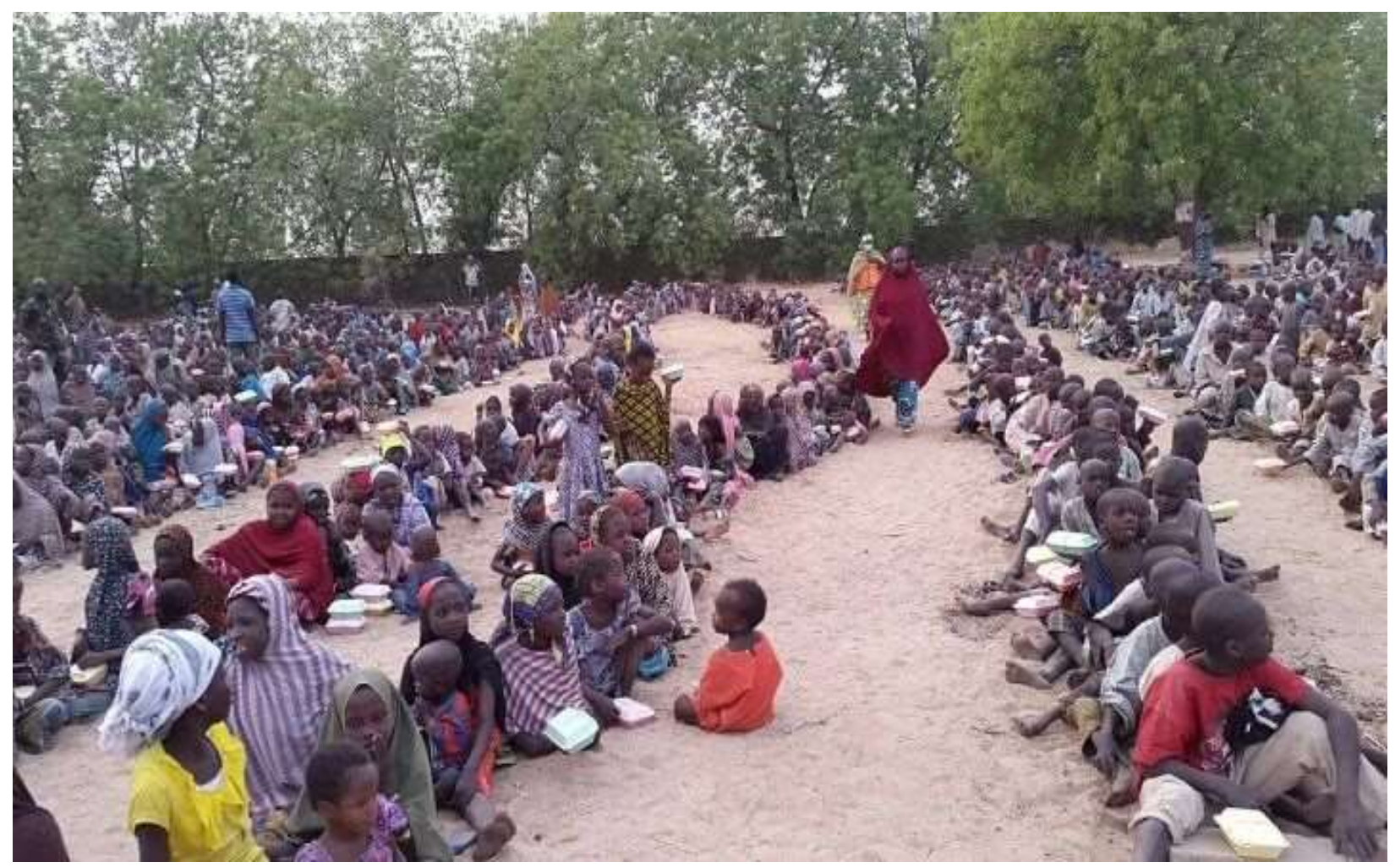

Figure 2: An IDP camp in North-East Nigeria.

Source: https://www.google.com.ng

Recently the IDPs in the camps are experiencing high level of security challenges such as kidnappings, stealing, raping and so on, on daily basis. This ugly situation has become a menace not only to the IDPs but also to the government, the communities and donor agents. Government concerns on how to manage and secure these camps and difficulty in distribution of relief materials to the IDPs by the donor agencies have become major issues. The manual method employed in keeping records of the IDPs in the camps has been an issue of great concern. The IPDs in the North-East Nigeria are experiencing serious security challenges in the camps because the manual method of identification is difficult and tedious.

This paper proposes a web-based fingerprint and facial identification system. Fingerprints are a form of biometric identification which is unique and does not change in one's lifetime. It has been proved over the years that fingerprints of different persons are unique (Cappelli et al, 2007). The biometric data that will be collected when analysed will make it easy for both the Government and donor agents to have the identities of the IDPs in the camps. It will also give a clear data for statistics for the Government and the donor agents and will also enhance the security of the IDPs. Kibuil (2010) states that biometric will make the registration and identification of refugees in camps easy and will provide exact numbers of refugees in these camps. The system will also monitor cross boarder movements and enhance the security, for people in a watch list will find it difficult to enter the country. The goal of this work is to design and implement a web-based fingerprint and facial identification system that will enhance the security, give proper identification and make distribution of relief materials easy to the IDPs in North-East Nigeria. It utilizes a portable fingerprint scanner as the input to acquire fingerprint images, a camera to capture picture (images) and a laptop computer as the mobile terminal to process the images. Personal data such as name, state, local government, town, age, sex are taken. 
The program incorporates fingerprint identification and recognition function as well as a database that stores the information of the IDPs in North-East Nigeria. Object Oriented Analysis and Design methodology (OOAD) were used to analyse the system and Unified Modelling Language (UML) was used to model the software. Web technologies such as PHP and MySQL were used for the database management system. The remaining parts of this paper are organized as follows: literature review, methodology, results, discussion, conclusion and an appendix.

\section{LITERATURE REVIEW}

In most parts of North-East Nigeria, the activities of insurgency have motorized communities to abscond from their traditional places of abode to various IDPs camps across North-East Nigeria. By 2014, the camps for IDPs were experiencing high level of security challenges such as kidnappings, stealing and rapes on daily basis which is a threat to IDPs; consequently the government is concerned about how to manage and secure these camps, and the difficulties in sharing of aids to IDPs by the donor agencies. Adamu and Zuwaira (2016) observed that the insecurity situation in contemporary Nigeria has forced large number of Nigerians to be vulnerable and susceptible to all forms of exploitation, abuse, neglect and many rendered homeless in North-East Nigeria and that the current number of IDPs camps across Nigeria shows that the Federal, States and Local Governments as well as host communities are all suffering from the effect of insecurity in the North-East. Obikaeze and Onuoha (2016) reported that despite the efforts made by Nigerian government, IDPs continue to face harsh conditions in the IDPs camps. They further stated that the armed groups unleash violent attacks on the IDPs, resulting to loss of innocent lives. Rotomi (2016) stated that of the problems faced by IDPs in the camps, insecurity ranks among the highest being the origin of their displacement. Living in the camps has not made them immune to rape, shootings and suicide bombing and random attacks from Boko Haram. These issues are difficult to address, given that the record processing system of IDPs is not robust enough to provide the needed information to the government and donor agencies.

Watson ( 2008) stated that fingerprints are the tiny ridges, whorls and valley patterns on the tip of each finger. They are created from pressure on a baby's tiny, developing fingers in the womb. There are no two persons that have the same fingerprints, they are totally unique. The chance of two persons having the same fingerprints is 1 out of 64 billion. Watson (2008) also mentioned in his work how fingerprint works, that fingerprints are even more unique than Deoxyribonucleic Acid (DNA), the hereditary material in each of our cells. Although identical twins can share the same Deoxyribonucleic Acid (DNA) or contain similar genetic materials, yet their fingerprints cannot be the same. Fingerprinting is a means of biometrics, which is a science that adopts people's physiological attributes to identify them and this, is because they are reliable and cannot change, even when they aged. Though feet and hands do contain many ridged areas that can be used for the purpose of identification, the popularity and wide adoption of fingerprints as a means of identification stem from the fact that they are easy to sort, classify and are readily accessible. Fingerprints are the arrangement of ridges, called friction ridges on one's fingers. Each ridge contains pores that are tied to sweat glands under the skin. (Kreimer 2011) stated that a palm scanner which reads a patient's unique vein pattern was implemented in sharp healthcare in San Diego for the purpose of stopping patient's identity theft. The system was known to be very secure and preformed efficiently well for its purpose.

According to Dubin (2013) the biometrics process has been discovered to be very helpful in the education sector where it has abetted students and school administration in the borrowing and returning of books out and into the library respectively. Xiang et al (2009) advanced a biometric model for examination screening and attendance monitoring. The model was done to prevent impersonation during examinations. The authors revealed that the use of biometric devices facilitated the reduction in impersonation since one student cannot misuse, forge or steal another student's biometric identity. 
According to Cappelli et al (2007) fingerprint - authentication is one of the most famous and revealed biometrics technologies. Because of their exceptionality and reliability over time, fingerprints have been in use for identification for over a century, more lately becoming automated due to developments in computed capabilities. Xiang et al. (2009) had done a research on archetype biometric security authentication system modeled on fingerprint recognition where the emphasis was on analyzing the fingerprint to test its efficiency. They projected a simple resourceful algorithm to identify and eliminate false minutia in order to convalesce the performance of the system. The percentage of FAR (false acceptance rate) and FRR (false reject rate) that was evaluated from the result ranged from 5.0 to $9.1 \%$ for FAR and 6.5 to $9.9 \%$ for FRR. This result markedly reveals the great accuracy of the developed fingerprint recognition system.

Fingerprints offer dependable process of personal identification. That is the essential explanation for their having recorded huge success in identifying the identities of criminals who are reluctant to admit previous arrests. Other personal characteristics do change but fingerprints do not. In ancient times, branding and maiming were used to spot the criminal for what he was. The criminal was deprived of his hand which was used in committing the act. However, the Romans employed the tattoo needle to identify criminals and also prevent desertion of mercenary soldiers. According to Kibuil (2010), biometric system will greatly transform the registration and identification procedures of refugees in the camp by providing the exact numbers of refugees in these associated camps. The system will also monitor cross-border movements which will enhance the security as people on a watch list will find it difficult to enter the country. As explained by Sunjic and Kathryn (2012), United Nations Humanitarian Commission for Refugee (UNHCR) conducted the first biometric registration exercise in South Sudan refugee camp, using digital fingerprinting technology.

The nearly 200,000 refugees had been registered in standard databases, but biometrics will help to identify refugees more quickly so they can receive better assistance. Ismail (2006) stated that Malaysia became the first country in Asia to launch UNHCR's new biometric registration system, which efficiently marries fingerprinting identification with UNHCR's refugee database system, called ProGres. Biometrics is a special, quantifiable distinctive attribute of a human being - in this case a fingerprint - for routinely diagnosing or substantiating identity. This is a vital stride for UNHCR Malaysia as it strengthens the security of registration system to prevent fraud, each fingerprint is unique, and no two are alike. By referring to this unique human feature, it is easy to decide if an individual is already enrolled in the system, and verify if an identity claim is true. For instance, if a prohibited asylum searcher tries to reapply for refugee status, the system will inevitably ascertain this. In the case of IDPs in the North-East camps, manual method of recording is employed and in some camps no records are kept.

Maurijana (2004) and Kausal (s2009) reviewed that biometric technology has assisted in controlling illegal entry of travelers into specific countries through the integration of biometric passport. The issue concerning how the false acceptance rate can be measured and detected in a border control setting was also interrogated. The researcher noted that the problems connected with biometric technologies such as error rates, spoofing attacks, non-universality and interoperability can be ameliorated through an overall security process that involves people, technology and procedures. Suggestions were given on how the security issues at the border can be solved. According to Benedicta (2012), there are two principal types of protection that forced migrants require. First, they need legal protection of their rights, particularly from return to situations that can compromise their safety. Second, they need physical protection to ensure their safety and security. A factor that undermines the legal safety of displaced girls and women is the issue of registration which is necessary, not only to establish legal standing, age and nationality but also to obtain assistance in many locations. In this regard, the overriding Principles on Internal Displacement which essentially constitutes a bill of rights for IDPs covering prevention, assistance, protection and return, in its Principle 20, state that every human being has the right to recognition everywhere as a person before the law. This principle stresses the duty of authorities to issue IDPs vital documents needed to exercise their legal rights and facilitate the issuance of new ones in the event that they are misplaced or damaged passports, personal identification documents, and birth and marriage certificates. UNHCR has described the benefits of a functioning registration system thus: Adequate registration, including the issuance of documentation, is a prerequisite for the lawful and physical protection of refugees. 
First, accessing assistance and services in implementing a set of civil rights, which must include protectionrelated rights (tracing, family reunification, freedom of movement, right not to be returned or expelled) flow from acknowledged and recorded refugee identity. Registration also ensures that each family member is independently recognized, which has important implications particularly for women and for children. Second, early and proper identification reduces multiple registrations and the use of fraudulent identity papers, particularly for the purpose of obtaining additional relief items. Third, registration is necessary to plan and implement refugee programs, to manage camps and to target protection and assistance activities at the field level. Fourth, states, UNHCR and operational partners require reasonably accurate population data to allocate resources, to monitor delivery and to evaluate interventions. Fifth, reliable registration information is necessary for the identification, planning and expeditious implementation of durable solutions.

Despite the above provisions, problems of inadequate process for registering and providing documentation persist. Physical insecurity is another big impediment to the protection of displaced women and children. Insecurity being defined as the absence of institutional guarantee against physical, emotional and psychological abuse and peril in the course of undertaking legitimate every day activity. In the conditions of armed conflict in Darfur, where the State is an active participant in the ongoing conflict and displaced persons are under its suzerainty, the security of displaced persons cannot be said to be in safe hands. Equally in North East Nigeria, IDPs are facing similar challenges like their counterparts in Darfur and refugees in refugee camps. This work designed and implemented a web-based fingerprint and facial identification system that will enhance the security, proper identification and easy distribution of relief materials to the IDPs in North-East Nigeria.

\section{METHODOLOGY}

The study was carried out based on desk-based research, looking at the existing literature. It was also empirical through field surveys in some of the formal camps in North-East Nigeria. It was conducted within the period of 3 months (November 2016 to January 2017) to allow for comparative analysis of the evolving situations on ground.

The field survey consisted of observations and interviews. The National Emergency Management Agency (NEMA) officials, some donor agencies and few IDPs in the camps were interviewed. In all the states of the North-East, at least 3 of the formal camps and one of the satellite or community camps were surveyed, some NEMA officials, donor agencies and a few of the IDPs were interviewed. The sampling methodology used was non-probabilistic sampling. However, the size of the sample was not proportional to the number of camps of interest. This is so because of the security situations in those areas. The developed system is web-base developed, using PHP, CSS, JAVA and MYSQL for managing the database. Object Oriented Analysis and Design Methodology (OOADM) and Unified Modeling Language (UML) were used to analyze the system and model the software respectively.

\subsection{Description of the Implemented System}

This study notes that the existing manual method of keeping records of IDPs in the camps is tedious and allows insecurity and improper documentation. A web-based application which provides a means of ensuring adequate documentations of IDPs by capturing the necessary data to ensure the proper identification and accounting of the IDPs is developed. Also, the use of fingerprint identification system which is a form of biometric identification is embedded in this application. The application utilizes a portable fingerprint scanner as its input in acquiring fingerprint and facial identification of the IDPs. It verifies the fingerprint by displaying the associated image and other personal details of the internally displaced person. 


\subsubsection{Flowchart of the Implemented System}

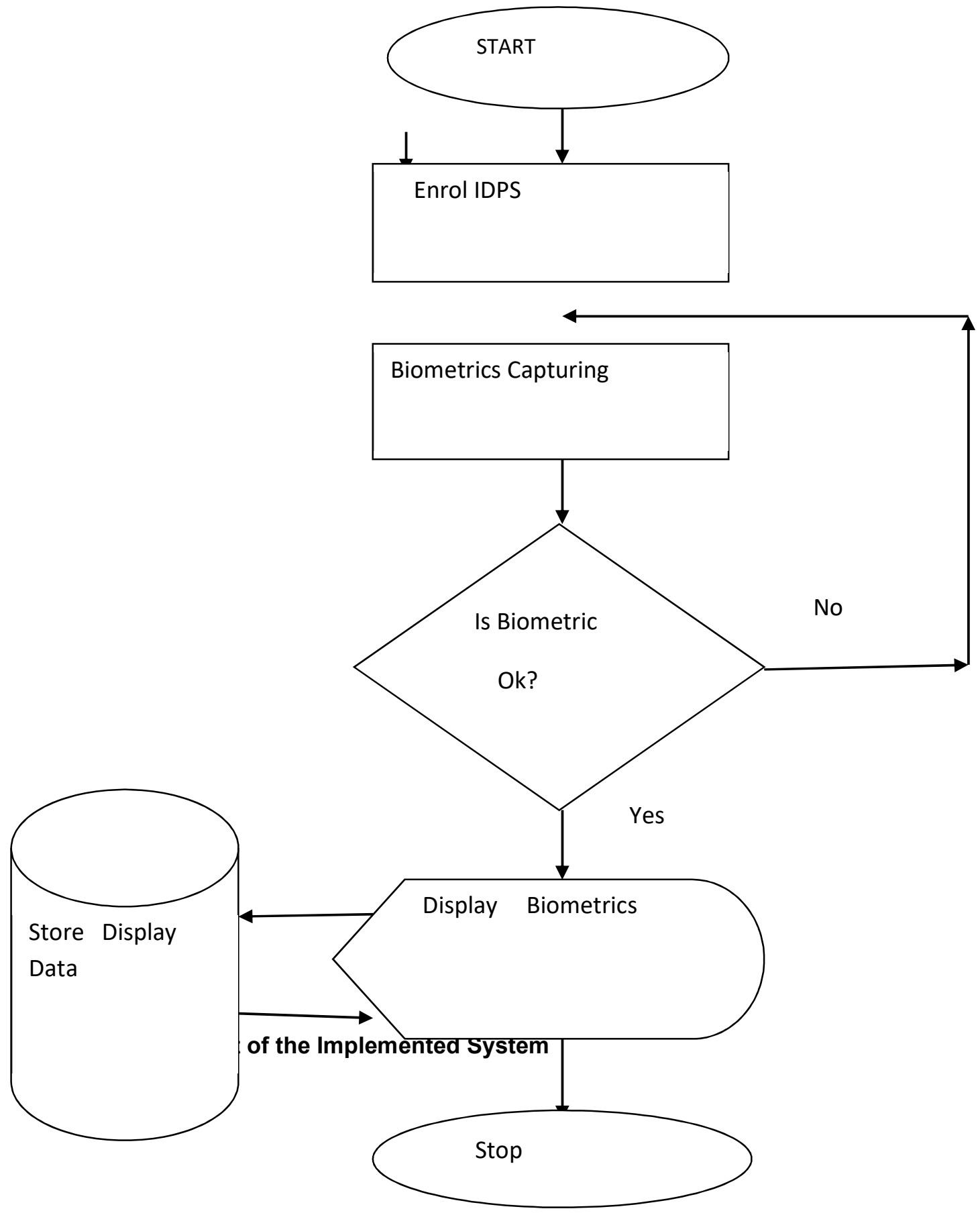




\subsubsection{Architecture of the Implemented System}

The developed system architecture was designed based on the presentation layer, the middle layer and the data layer. The presentation layer shows the programming which provides the graphical user interface (GUI) and application specific entry forms or interactive windows. The middle layer or business logic acts as the server for client requests from workstations. The data layer includes the database and a program to manage, read and write access to it. MYSQL is the database management system used in the development of this system.

Server

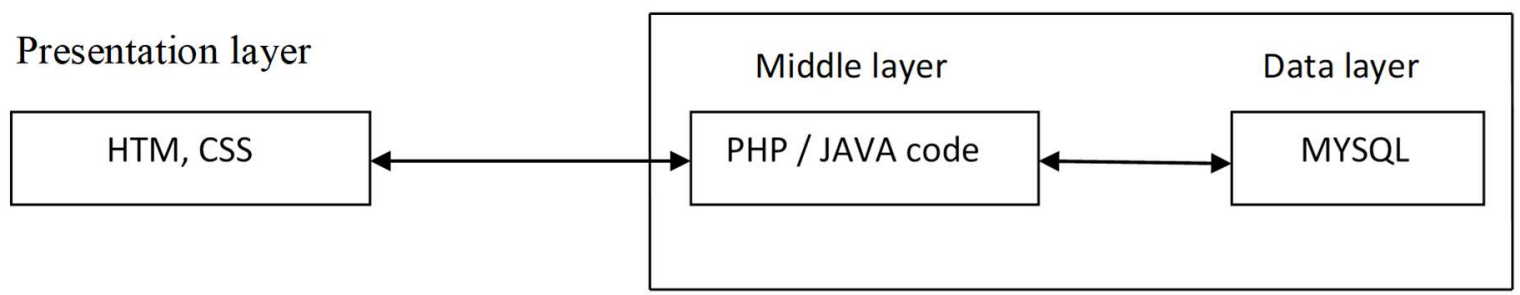

Figure 4: Architecture of the Implemented System

\subsubsection{Implementation Architecture}

This is a diagram that shows the various components of the system and their connections.

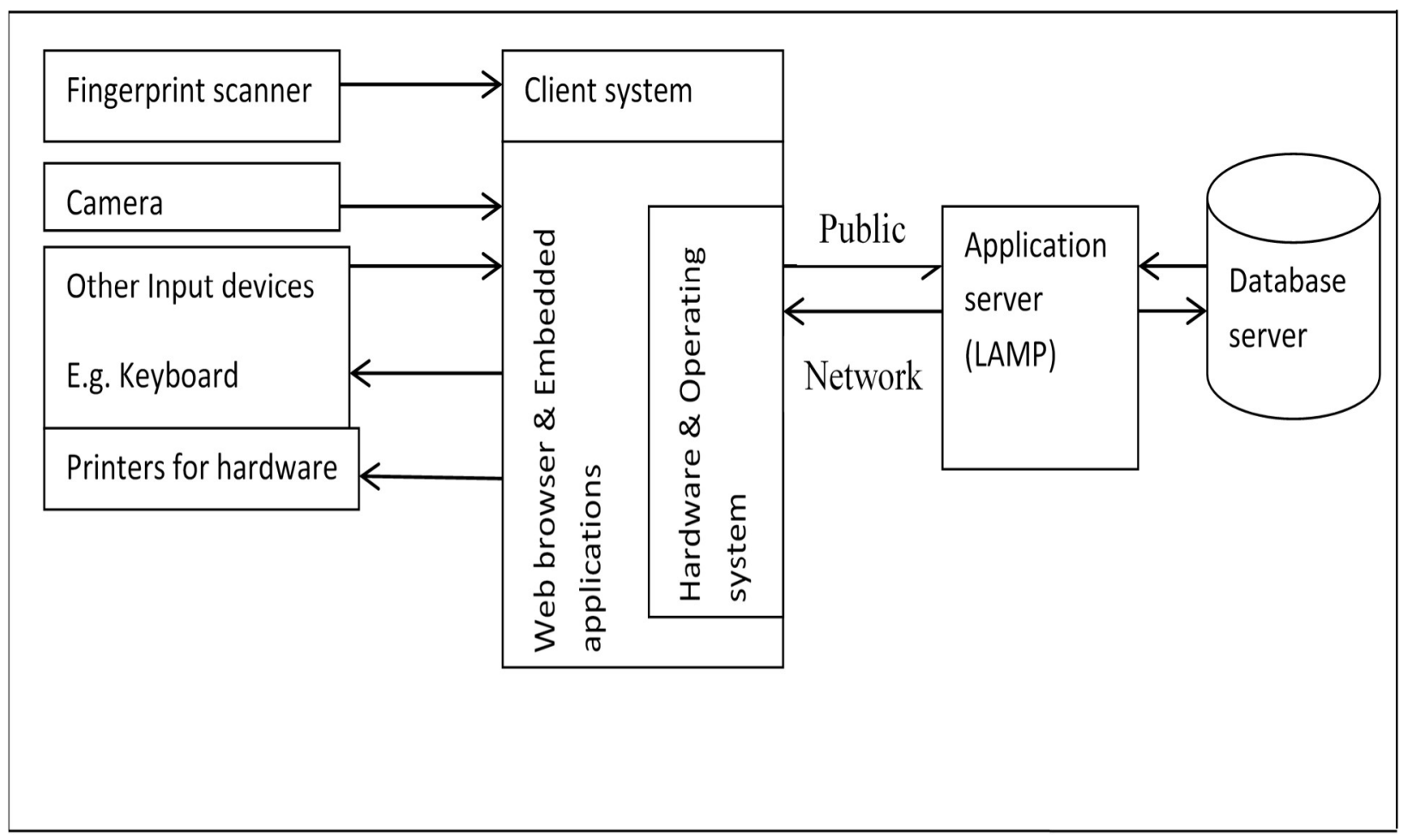

Figure 5: Implementation Architecture of the System 


\section{RESULTS AND DISCUSSIONS}

The implemented system is a system that captures the fingerprints of the IDPs and is web based. This system was implemented using PHP, JAVA and MYSQL. It involves the interaction with the central database which contains records of the IDPs. The process involves enrolment of each IDP in a given camp and capturing of their fingerprints and the verification of the captured fingerprints. Each IDP can be enrolled and the record can be retrieved and viewed, the design requirements are met through the use of a fingerprint scanner which captures the fingerprints of IDPs and desirable results are archived, some of which are discussed as:

\subsection{IDPs Enrolment}

This is where the internally displaced persons are enrolled, giving their bio data.

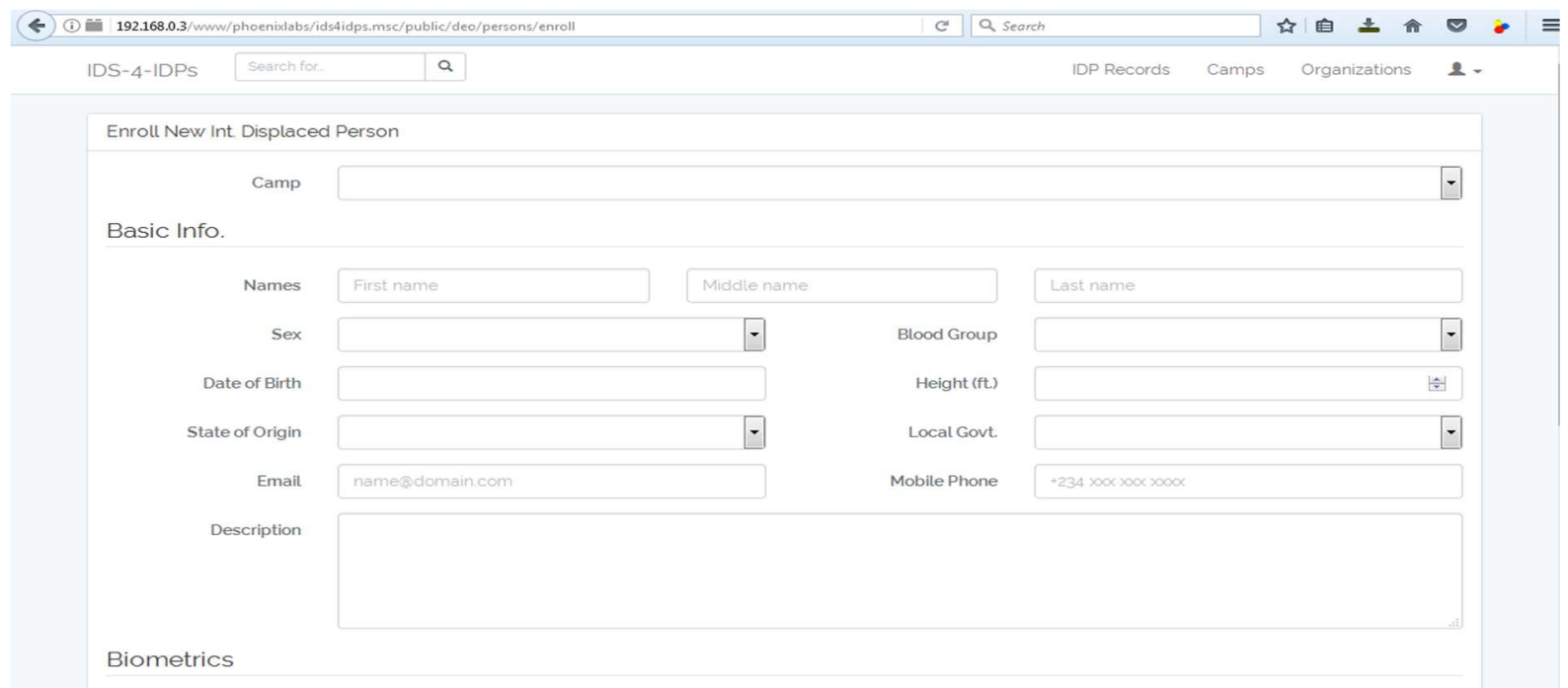

Figure 6: Enrolments of IDPs

4.2 The Fingerprints and Facial Identification of the IDPs are captured into the database.

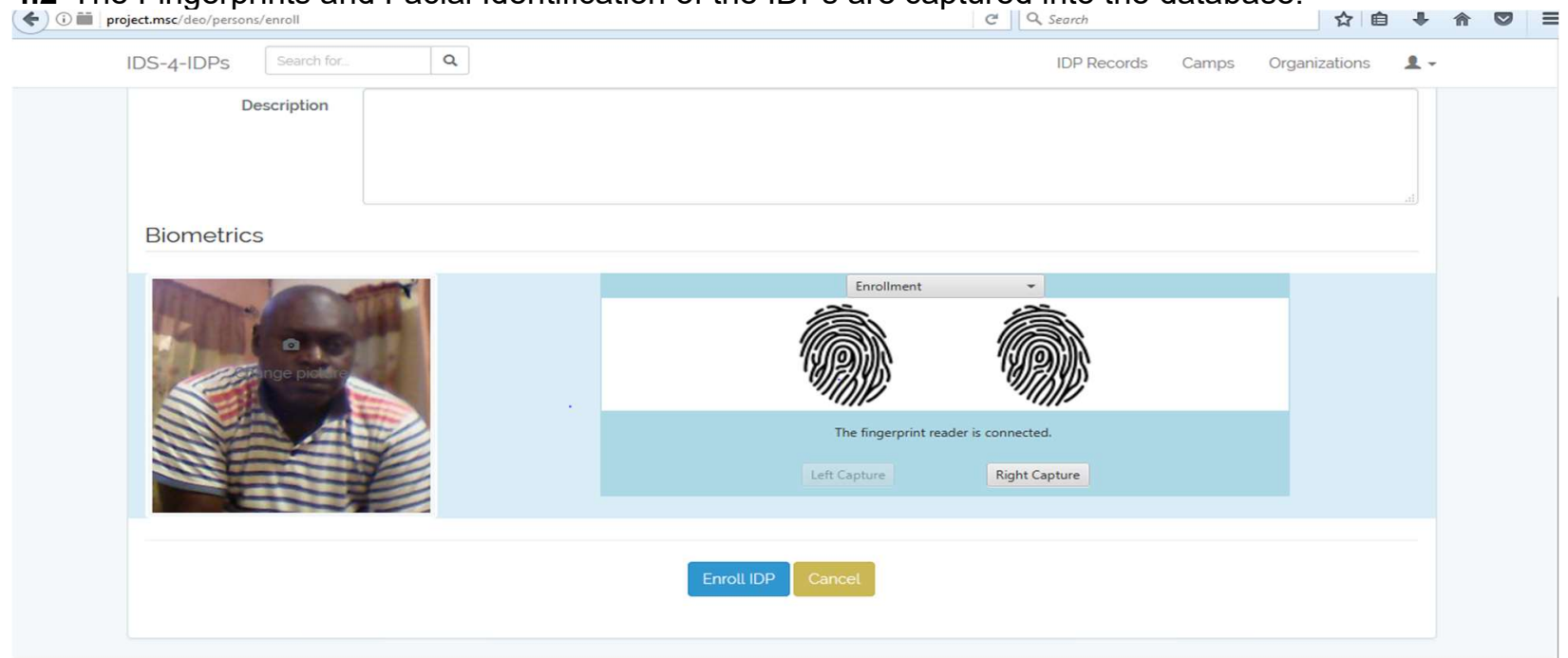

Figure 7: Capturing fingerprints/facial identification 


\subsection{The IDPs captured fingerprints are being verified for proper identification}

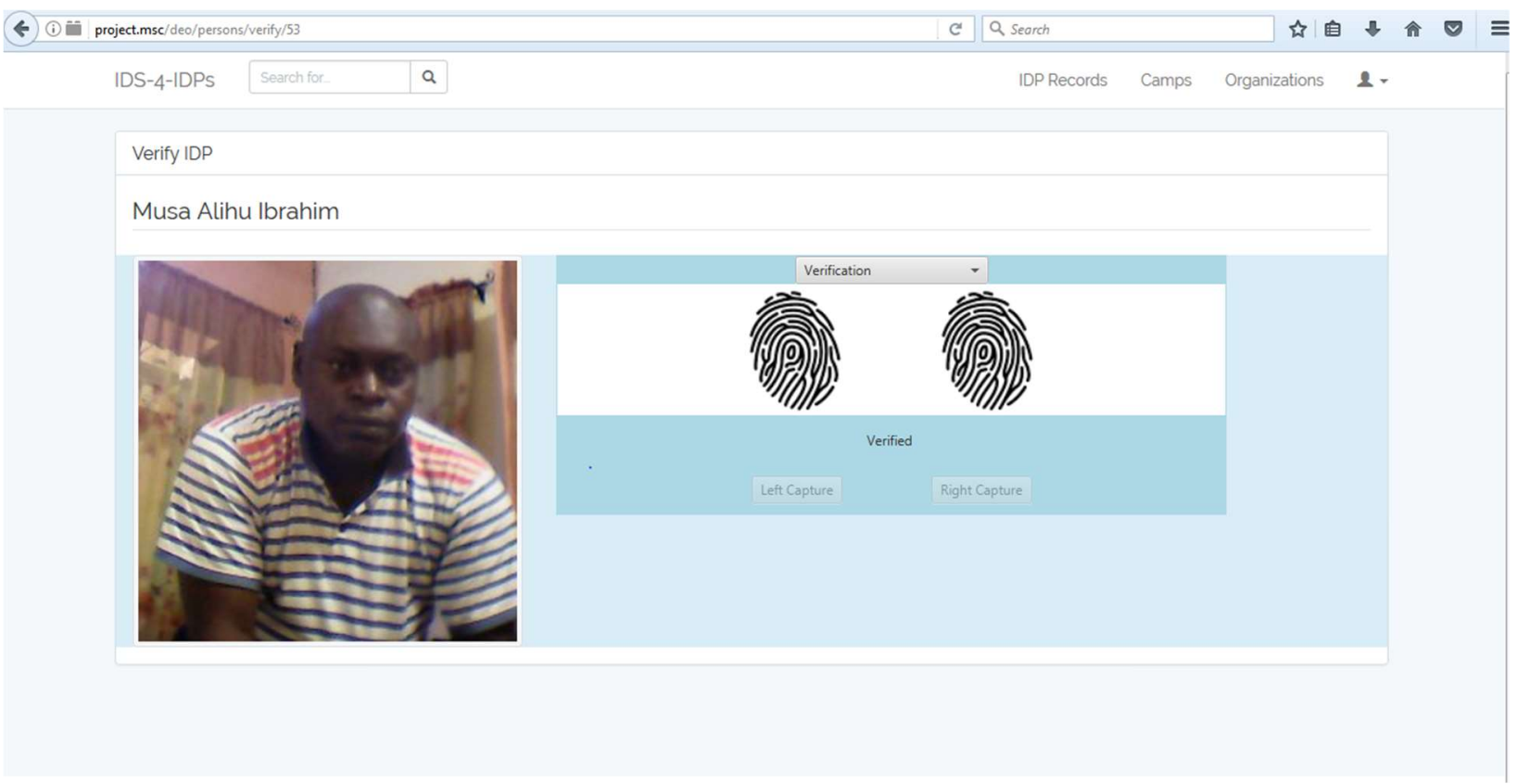

Figure 8: Verification of the IDPs fingerprints

\section{CONCLUSION}

The registration of Internally Displaced Persons (IDPs) in the camps across the North-East Nigeria has been the manual method, which involves pen and paper registers. This work designed and implemented a web-based system using fingerprint and facial identification for the IDPs in North-East. This will greatly reduce the insecurity in the camps. The system will also improve the monitoring of IDPs and the security of the camps. It will also assist the donor agencies in the distribution of relief materials to the IDPs and the government for future planning. 


\section{REFERENCES}

1. Adamu A. and Zuwaira R. H, (2016). Effects of Insecurity on the Internally Displaced Persons (IDPs) in Northern Nigeria: Prognosis and Diagnosis. Global Journal of Human-Social Science (f) Xvi (1),version 1.0, 1-7. [Accessed on $19^{\text {th }}$ May 2016]

2. Benedicta D., (2010). Plight of Displaced Women and Children in Africa: A Case Study of Darfur Crisis. Nails Law and Development Journal www.nails-nigeria.org/journal/benedicta. 231-253 [Accessed on $17^{\text {th }}$ April 2017]

3. Cappelli R., Maio D. , Maltoni D.,Wayman J. and Jain A.(2007). "Performance Evaluation of Fingerprint Verification System". Computer Journal of IEEE Transaction on Pattern Analysis and Machine Intelligence. 28(1), 55-59. [Accessed on $10^{\text {th }} \mathrm{Feb}$ 2017]

4. Obikaeze, Victor Chibuike and Onuoha, Chijioke Basil O. (2016). "The Nigerian- State and Management of Internally Displaced Persons (Idps) From 2012-2016." African Journal of Politics and Society, 1-21. [Accessed on $6^{\text {th }}$ August 2016]

5. Dubin, C. (2011). 'Biometrics: Hands Down', ID Management. Security, February 1, 52, 54. http://proquest. umi. [Accessed on $5^{\text {th }}$ March 2017] com/pqdweb?index=0\&did=2277161341\&SrchMode=1\&sid=2\&Fmt=6\&VInst=PROD\&VType=PQD\&R $\mathrm{QT}=309 \& \mathrm{VName}=\mathrm{PQD}$

6. Emmanuelar, I. (2015). Insurgency and Humanitarian Crises in Northern Nigeria, the Case of Boko Haram. African Journal of Political Science and International Relations. 9(7), 284-296. [Accessed on $10^{\text {th }}$ May 2016]

7. http://science.howstuffworks.comfingerprinting1.html

8. http://www.thecable.ng/idps-Nigeria-Insecurity-Insecurity Dec 2016 "The Cable, Idps in Nigeria: From Insecurity to Insecurity"

9. http://www.usmarshals.gov/usmsforkids/fingerprint history.html

10. Ismail Y. (2006). Fingerprints Mark the New Direction in Refugee Registration." Unhor the UN Refugee Agency, Ed. K. Mckinsey.Journal of Forensic Science, 4(2), 221-0741 [Accessed on 24 ${ }^{\text {th }}$ Jan 2017]

11. Kaushal N. (2009). Fingerprints: Historical Background and Future Trends. The Internet Journal of Forensic Science. 4(2), 1-5.

12. Onor Kester Chukwuma and Okechukwu Groupson-Paul UC(2017). Human Security Challenges in the Horn of Africa and the Precarious Contours in Managing Regional Security Problems. Nnamdi Azikiwe Journal of Political Science 5(1),135-155

13. Kibuil M. Samuel (2010). Requirements Engineering for a Biometric Based System in Refugee Camp Management: A Case Study of the Dadaab Refugee Camp. A Research Project Submitted In Partial Fulfilment of the Requirements for the Degree of Master of Business Administration, School of Business, Department of Management Science, University of Nairobi.

14. Kreimer .S. (2010). Matching the Right Patient to the Right Record. Hospitals \& Health Networks, November $1, \quad 12 . \quad$ http://proquest.umi.com/pqdweb?index=0\&did=2212480 $041 \&$ SrchMode $=1 \&$ sid $=1 \& \mathrm{Fmt}=6 \&$ VInst $=$ PROD\&VTy pe $=P Q D \& R Q T=309 \& V$ Name $=P Q D \& T S=1304102414 \&$ client $I D=13314$.

15. Maurijana K. (2004). Passport of the Future, Biometric Against Identity Theft. MSc Thesis in Information Security, Norwegian Information Security Laboratory.

16. Mohammed F.K. (2017). The Causes and Consequences of Internal Displacement in Nigeria and Related Government Challenges. Working Paper FG 8 April 2017 Swp Berlin

17. Rufai M .M, Adigun J. O, Yekini N. A (2012). A Biometric Model for Examination Screening and Attendance Motoring in Yaba College of Technology. World of Computer Science and Information Technology Journal (Wcsit) ISSN. 2221-0741.2(4), 120-124. [Accessed on $1^{\text {st }}$ March 2017]

18. Sunjic H. Melita and Kathryn M. (2012). Modern Technology Helps Meet the Needs of Refugee in South Sudan. Unhcr the UN Refugee Agency, ed. J. Redden, 27 Dec. 2012. [Accessed on 4th Jan 2017]

19. WATSON S. (2008). How Fingerprint Works. Science / Forensic Science. https://science.howstuffworks.com/fingerprinting.htm

20. Www.Premiumtimesng.Com/Region/North-East

21. Xiang W., Desai B., Wen P., Wang Y. Peng T. (2009). A Prototype Biometric Security Authentication System Based Upon Fingerprint Recognition, Springer Berlin Heidelberg. $4^{\mathrm{TH}}$ International Conference, Rskt 2009, Gold Cost, Australia, July (14-16, 2009). 264-272. [Accessed on30th Feb 2017] 
Advances In Multidisciplinary Pins \& Scientific Research

\section{APPENDIX}

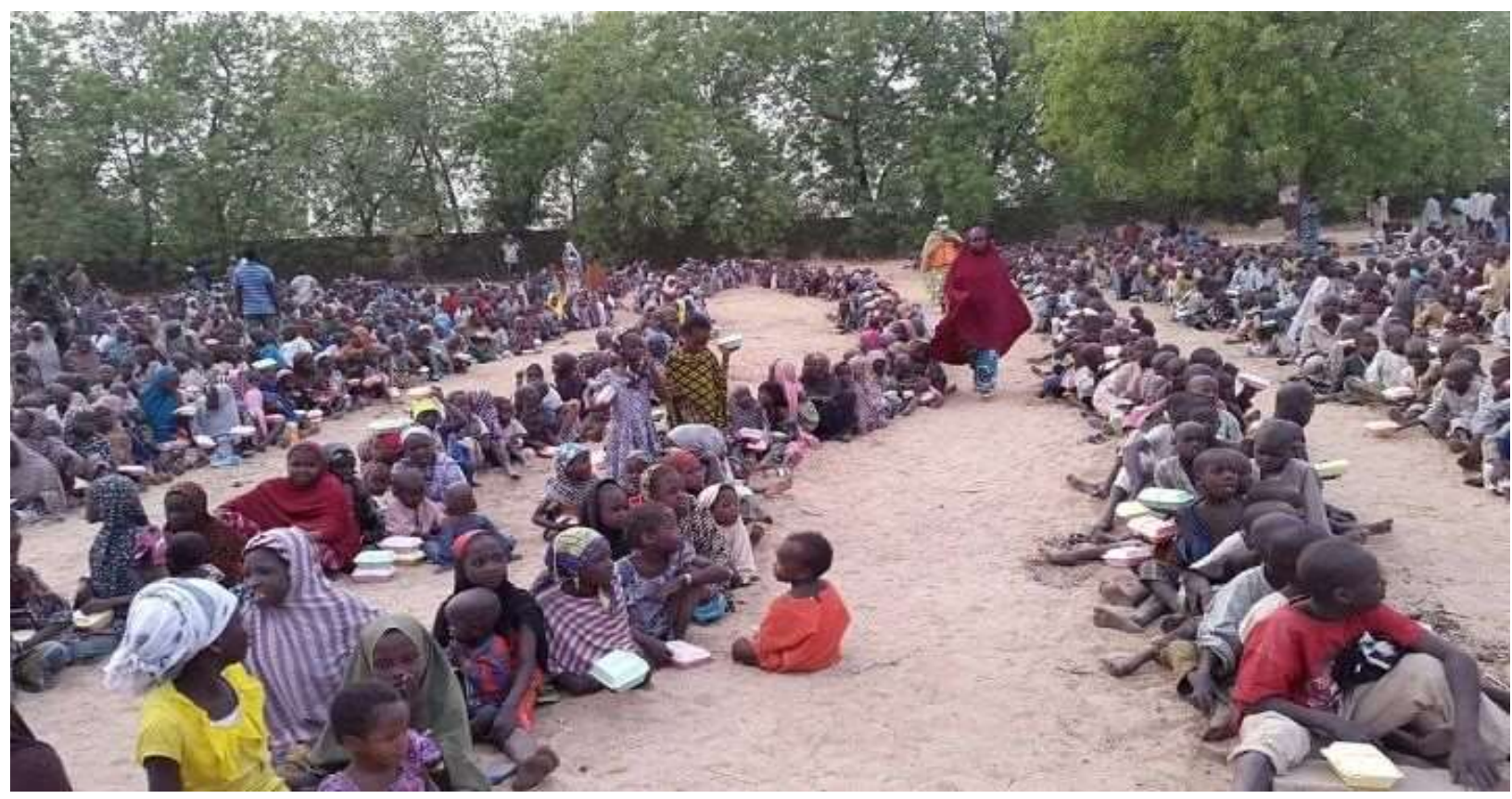

A IDPs camp in NE Nigeria:

Source:https://www.google.com.ng

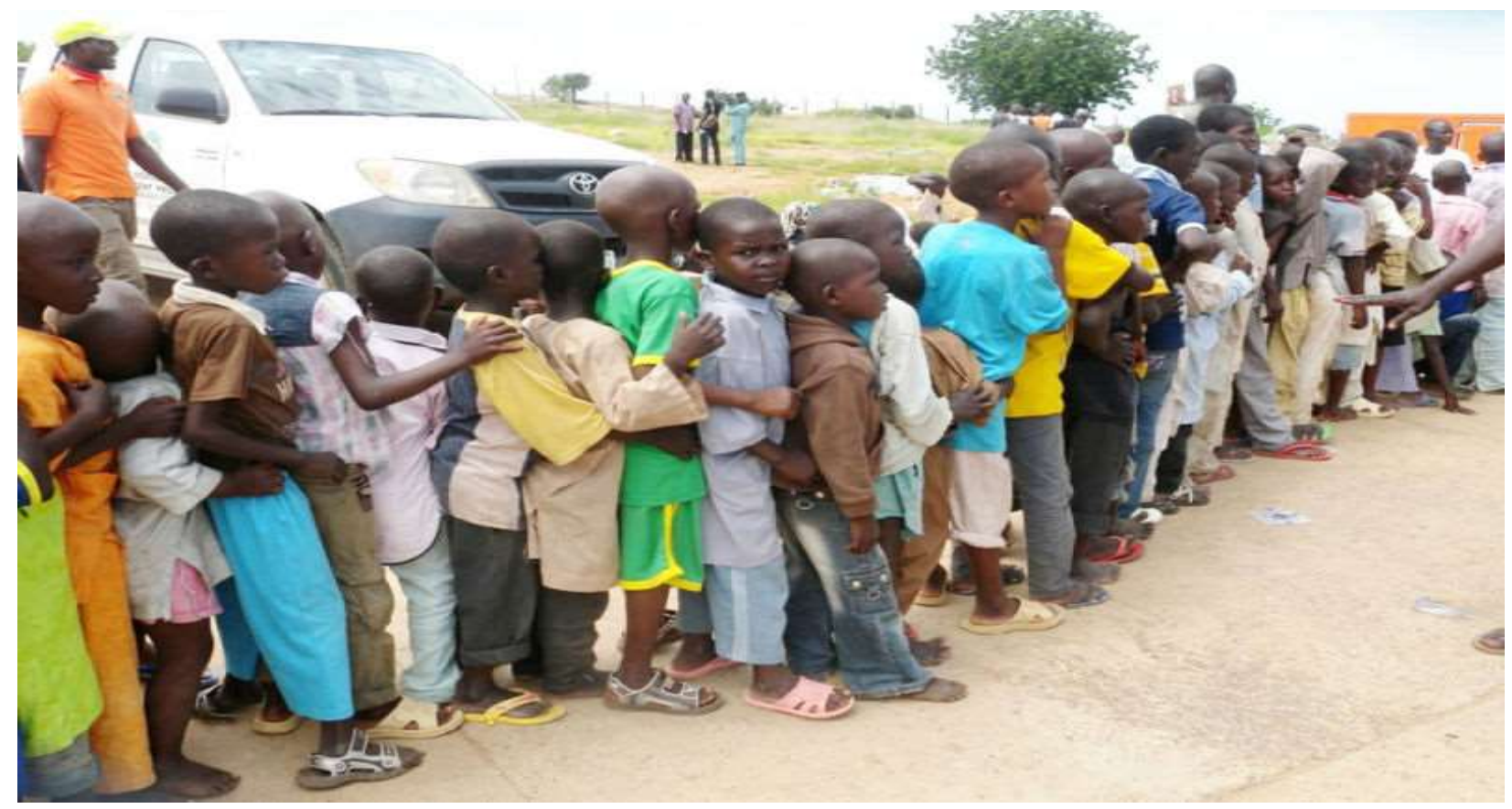

Displaced children (boys) line up for relief

Source:https://www.google.com.ng 
Advances In Multidisciplinary Ainis \& Scientific Research A Multidisciplinary \& Interdisciplinary Journal

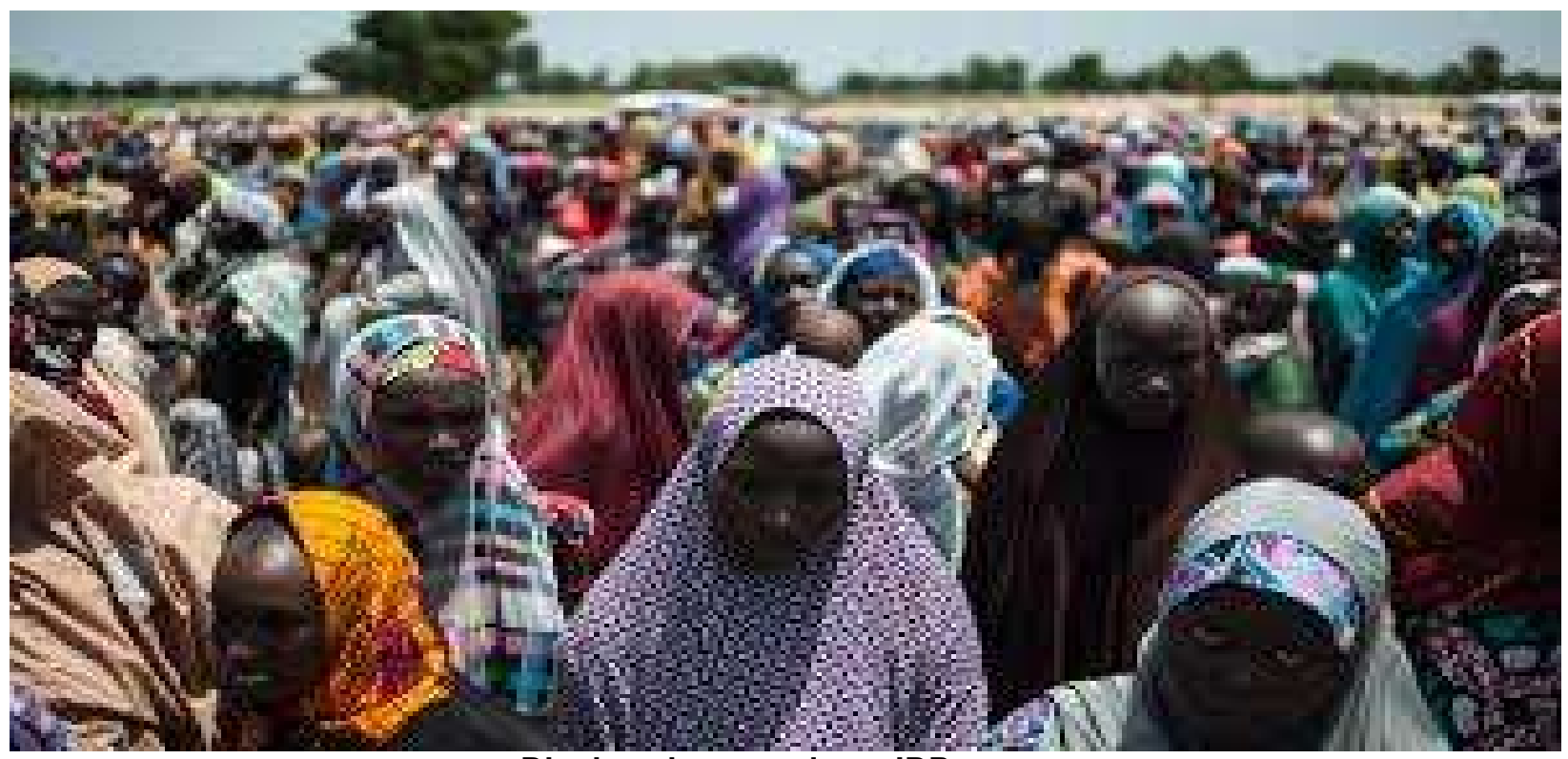

Displaced women in an IDP camp

Source:https://www.google.com.ng

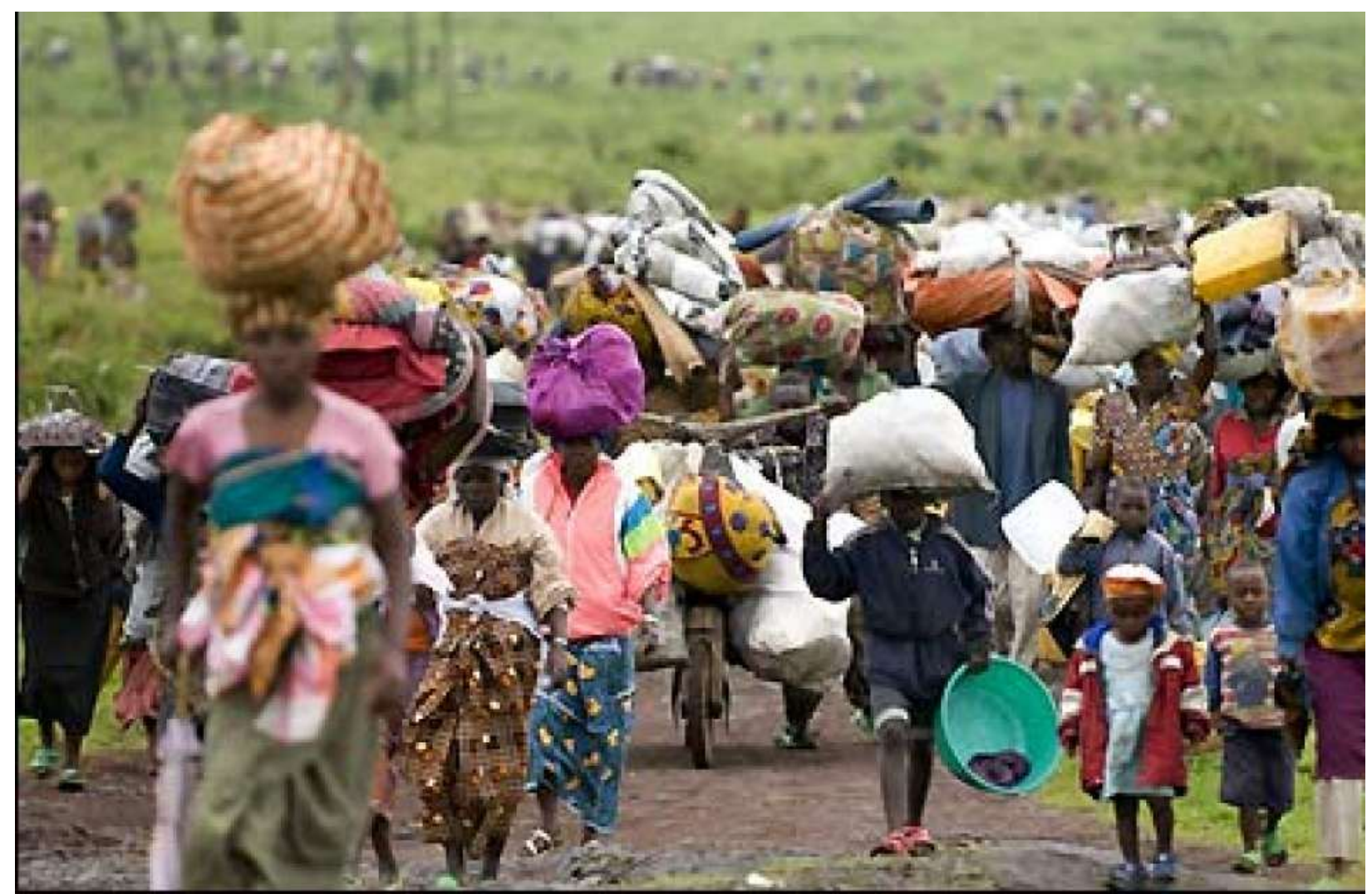


Advances In Multidisciplinary

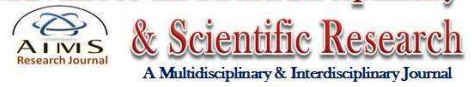

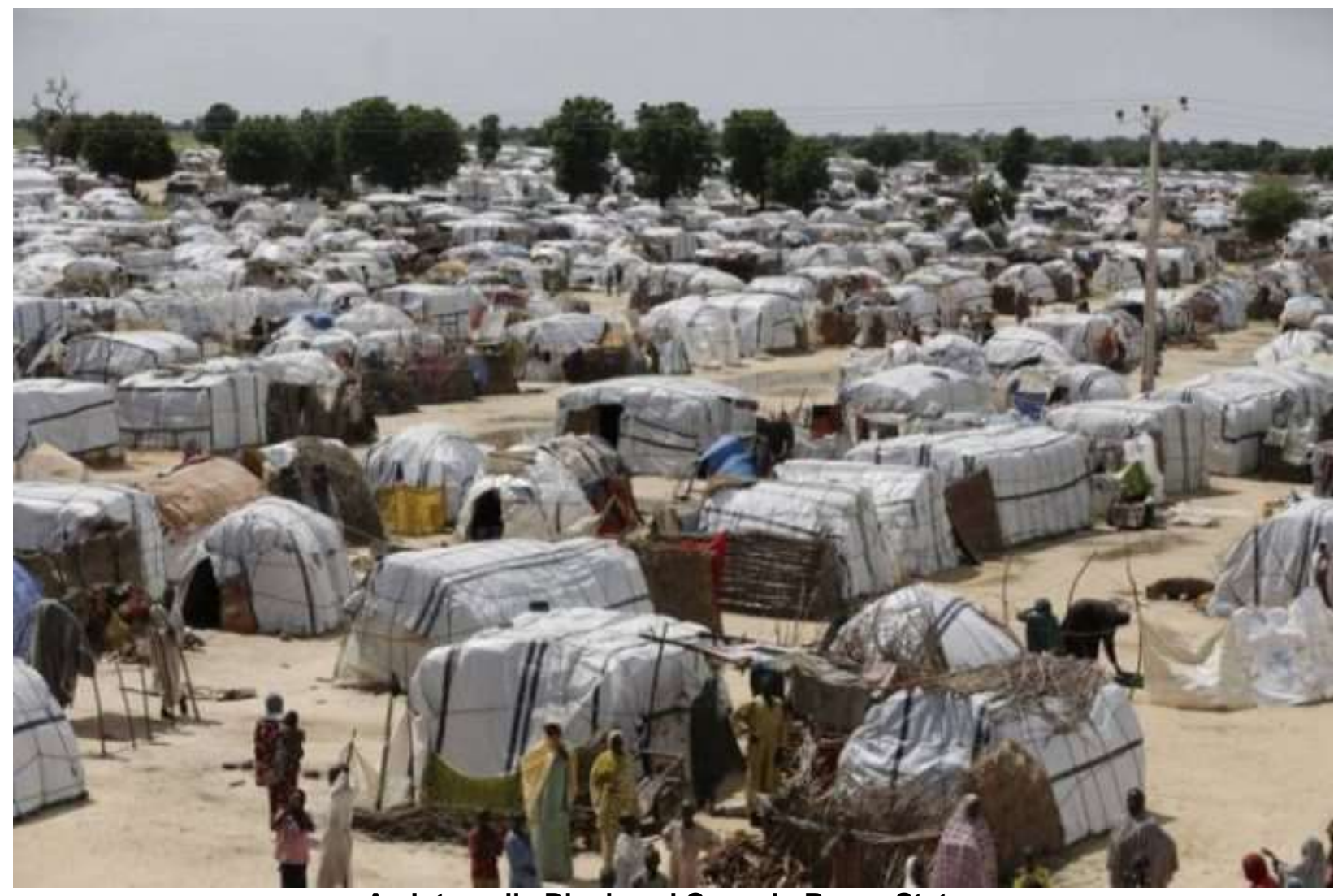

An Internally Displaced Camp in Borno State.

Source:https://www.today.ng/news/nigeria/9835/boko-haram-kills-11-borno-idp-camp 